\title{
Are We on the Right Track: Can Our Understanding of Abscission in Model Systems Promote or Derail Making Improvements in Less Studied Crops?
}

\author{
Sara E. Patterson ${ }^{1 *}$, Jenny L. Bolivar-Medina ${ }^{1,2}$, Tanya G. Falbel' ${ }^{1}$, Janet L. Hedtcke ${ }^{3}$, \\ Danielle Nevarez-McBride ${ }^{1}$, Andrew F. Maule ${ }^{1}$ and Juan E. Zalapa ${ }^{1,2}$
}

${ }^{1}$ Department of Horticulture, University of Wisconsin-Madison, Madison, WI, USA, ${ }^{2}$ Vegetable Crops Research Unit, United States Department of Agriculture - Agricultural Research Service, Madison, WI, USA, ${ }^{3}$ West Madison Agricultural Research Station, Verona, WI, USA

OPEN ACCESS

Edited by:

Timothy John Tranbarger, Institut de Recherche pour le

Développement, France

Reviewed by:

Hiroaki Iwai,

University of Tsukuba, Japan

Luis F. Goulao,

Tropical Research Institute, Portugal

Urs Fischer,

Umeå Plant Science Centre, Sweden

*Correspondence: Sara E. Patterson spatters@wisc.edu

Specialty section: This article was submitted to Crop Science and Horticulture, a section of the journal

Frontiers in Plant Science

Received: 16 October 2015

Accepted: 28 December 2015

Published: 26 January 2016

Citation:

Patterson SE, Bolivar-Medina JL,

Falbel TG, Hedtcke JL,

Nevarez-McBride D, Maule AF and Zalapa JE (2016) Are We on

the Right Track: Can Our

Understanding of Abscission in Model

Systems Promote or Derail Making

Improvements in Less Studied

Crops? Front. Plant Sci. 6:1268.

doi: $10.3389 /$ fpls.2015.01268
As the world population grows and resources and climate conditions change, crop improvement continues to be one of the most important challenges for agriculturalists. The yield and quality of many crops is affected by abscission or shattering, and environmental stresses often hasten or alter the abscission process. Understanding this process can not only lead to genetic improvement, but also changes in cultural practices and management that will contribute to higher yields, improved quality and greater sustainability. As plant scientists, we have learned significant amounts about this process through the study of model plants such as Arabidopsis, tomato, rice, and maize. While these model systems have provided significant valuable information, we are sometimes challenged to use this knowledge effectively as variables including the economic value of the crop, the uniformity of the crop, ploidy levels, flowering and crossing mechanisms, ethylene responses, cultural requirements, responses to changes in environment, and cellular and tissue specific morphological differences can significantly influence outcomes. The value of genomic resources for lesser-studied crops such as cranberries and grapes and the orphan crop fonio will also be considered.

Keywords: abscission, shedding, seed-shatter, grape, cranberry, fonio, tomato

\section{INTRODUCTION}

Historically, humans have selected crop plants with delayed abscission for generations, as early fruit drop or seed shatter limited effective collection of the fruits, grains, or legumes (Harlan, 1992; Plants and Society, 2006). In general, we know the process of abscission results in shedding of organs as a developmentally programmed event; however, abscission may also occur in response to pathogens, environmental cues or other stresses. Early studies on abscission focused on the anatomical and physiological characterization of the abscission zone (Addicott, 1982; Sexton and Roberts, 1982). These studies have shown that the abscission zone consists of a few to multiple cell layers and is distinguished by small densely cytoplasmic cells. During the abscission process, there is breakdown of the middle lamella of cells within the separation layers. Although historically, there have been several proposed models for genes regulating abscission, scientists are still unclear 


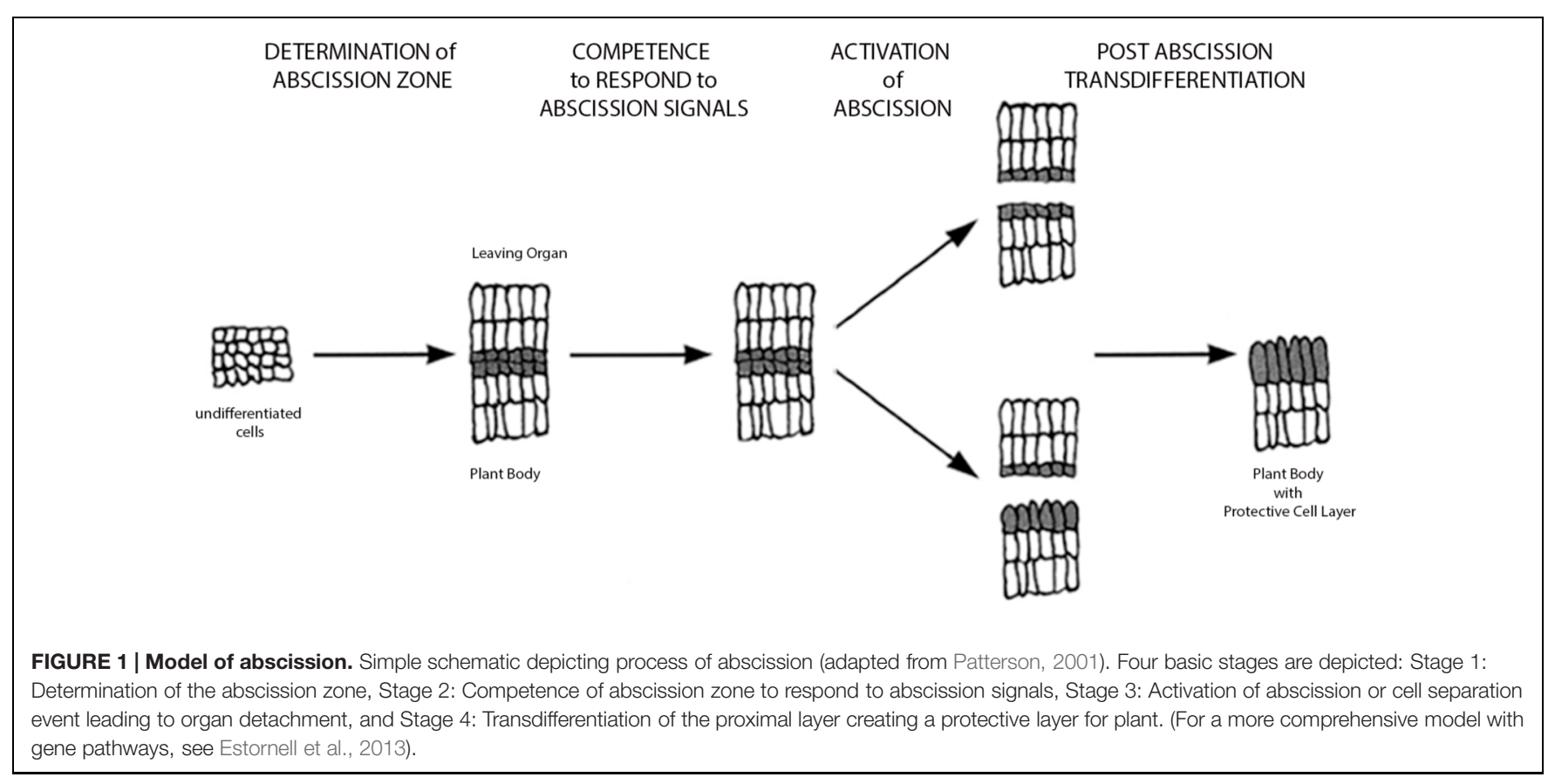

as what are the key players and how plant hormones, like ethylene, jasmonic acid (JA), abscisic acid, and auxin affect the regulation of gene expression during the process (Figure 1). There is strong evidence for interplay between the plant hormones ethylene and auxin in regulating abscission timing, where the former enhances the process and the latter inhibits (Abeles and Rubinstein, 1964; Jensen and Valdovinos, 1967; Addicott, 1982; Osborne, 1989). In addition, early researchers also focused on elucidating the role of cell degrading enzymes including the polygalacturonases and cellulases during the abscission process (Abeles, 1969; del Campillo and Bennett, 1996; del Campillo, 1999). Model systems including rice, maize, Arabidopsis, and tomato have provided new valuable genetic information on abscission and shattering, and knowledge of these genes associated with abscission has the potential to radically change approaches to studying abscission (Lewis et al., 2006; Estornell et al., 2013; Niederhuth et al., 2013).

\section{Abscission in Monocots}

In the grasses (maize, sorghum, and rice), initially two transcription factors were identified as associated with the regulation of shattering, qSH1 and SH4 (Konishi et al., 2006; Li et al., 2006). SHAT1, an APETELA2 transcription factor, has also been identified as a gene that also affects shattering (Zhou et al., 2012). These genes are key factors in eliminating most shattering in members of the Poaceae family. In addition, homeodomain-leucine zipper transcription factors (HD-Zip TFs) and genes associated with growth regulation including auxin and ethylene responses from sorghum and maize are expressed in floral abscission zones (Chew et al., 2013; Dwivedi et al., 2014). Most recently, BRITTLE RACHIS1 and 2 were identified in barley and shown to be responsible for seed shatter (Pourkheirandish et al., 2015). Especially interesting is the fact that BRI1, 2 are hypothesized to act as receptor and ligand and BRI2 has been shown to have homology with the Arabidopsis protein IDA that is also hypothesized as a receptor ligand (Butenko et al., 2003; Pourkheirandish et al., 2015). Orphan grain crops such as Digitaria exilis (fonio), Eragrostis tef (teff), and Eleusine coracana (finger millet) often have major losses due to early or unregulated shattering, and thus could highly benefit from breeding for delayed abscission and abscission associated genes through introgression of favorable alleles. While genes such as qSH1, SH4, and SHAT1 have been shown to regulate shattering in domesticated rice, recent studies also show that panicle structure may also be critical (Ishii et al., 2013). Thus, undue attention to only specific genes or a single trait rather than multiple gene traits, might result in less effective selection.

\section{Abscission in Dicots: Arabidopsis as Model System}

In dicots, Arabidopsis has served as the model system to study abscission, and researchers have gained significant insights concerning regulation of the abscission process. Genes regulating development of the abscission zone and responses to hormonal, environmental, and newly discovered endogenous signals regulating abscission have been extensively studied. There are many excellent reviews: (Roberts et al., 2000, 2002; Aalen et al., 2006, 2013; Binder and Patterson, 2009; Van Nocker, 2009; Liljegren, 2012; Estornell et al., 2013; Niederhuth et al., 2013). While considerable inroads have been made on understanding the genes involved in signaling, the exact pathways are still being defined (Liljegren, 2012; Niederhuth et al., 2013). These key players include IDA (Butenko et al., 2003, 2009; Stenvik et al., 2008), HAESA (Jinn et al., 2000), HAESA LIKE (Shi et al., 2011), NEVERSHED (Liljegren 
et al., 2009), and EVERSHED (Leslie et al., 2010). Additional downstream signaling factors have also been identified and include SERK1, BREVIPEDICELLUS/KNOTTED-LIKE FROM ARABIDOPSIS THALIANA (BP/KNAT1; Wang et al., 2006; Shi et al., 2011), and MAP kinases (Meng et al., 2012). Genes that are critical for formation of the abscission zone in Arabidopsis include BOP1 and BOP2, and the MADS BOX gene AGL15 (Fernandez et al., 2000; Hepworth et al., 2005; McKim et al., 2008).

Additional transcription factors that have been identified include FOREVER YOUNG FLOWER (FYF; Chen et al., 2011) and the zinc finger protein Arabidopsis ZINC ZINGER PROTEIN 2 (Cai and Lashbrook, 2008). While these genes have been shown to be involved in the abscission process, the actual function during the abscission process is quite undefined. Similarly, genes regulating organ boundary patterning and elasticity of boundaries have been identified and while many have no determined role, the F-box gene HAWAIIAN SKIRT has been shown to disrupt normal patterning leading to fusion of sepals, and consequently delayed abscission (Aida and Tasaka, 2006; Gonzalez-Carranza et al., 2007b; Rast and Simon, 2008). An additional F-box gene COI1 also delays abscission; however, it has been determined that this delay is most likely due to altered regulation of ethylene and auxin responses during the process of abscission in response to the absence of JA signaling rather than formation of the abscission zone (Kim et al., 2013). And, while the role of JA during abscission was initially a surprise, the role of other hormones such as ethylene and auxin during abscission has been well characterized in Arabidopsis (Patterson and Bleecker, 2004; Ellis et al., 2005; Binder and Patterson, 2009; Ogawa et al., 2009; Basu et al., 2013; Kim, 2014). These include ethylene synthesis genes (ALLENE OXIDE SYNTHESIS), ethylene response genes (ETR1, EIN2, and EIN3) and auxin-associated genes (ARF1, ARF2, and AUX1).

Many genes regulating cell wall modifications have also been identified and studied for their role in abscission in Arabidopsis as well as other species. These include polygalacturonases (Gonzalez-Carranza et al., 2002, 2007a; Kim and Patterson, 2006; Kim et al., 2006), cellulases (del Campillo, 1999), expansions (Cho and Cosgrove, 2000; Lashbrook and Cai, 2008), pectate lyases, xyloglucans and glycosylase transferases (Lashbrook and Cai, 2008; Wei et al., 2010; Singh et al., 2011). In addition, determination of unique morphological characteristics of the abscission zone have been characterized by multiple research groups: cell number, scar formation, timing and the relationship to environmental stresses, and developmental processes such as pollination, fertility, and senescence (Sawicki et al., 2015). There are also new studies indicating that alkalization of the cytosol of cells within the abscission zone is particularly important (Sundaresan et al., 2015). Last, cell death markers including $L Z$ ribonuclease and BFN1 nuclease have been characterized for their roles during the abscission process (Farage-Barhom et al., 2008; Bar-Dror et al., 2011). In summary, there are many genes identified in Arabidopsis that impact the process of abscission and additional research will be needed before all the key players are characterized.

\section{Abscission in Dicots: Tomato as Model System}

Abscission in tomato has also been studied quite extensively, as tomato has been considered a model crop that is relatively easy to work with: true breeding (self pollinated), moderate sized genome (900 Mb), excellent isogenic stock collections, well characterized genetics, excellent physiological research studies, and easily transformed. Genome information, gene expression, and information about isogenic genetic stocks are available through the tomato functional genomics database (TFGD), the Sol Genomics network (http://solgenomics.net/) and NCBI. While there is considerable knowledge about genes regulating abscission within the pedicel in jointed tomatoes JOINTLESS (Mao et al., 2000; Nakano et al., 2013; Guan et al., 2014; Ito and Nakano, 2015), there is still relatively little understood concerning regulation of abscission at the fruit pedicle junction. These distinctions are valuable in terms of marketing different types of tomatoes (cluster on the vine versus slicing) and in shipping. In jointed tomatoes (see Figure 2) abscission within the pedicel or at the knuckle has been shown to be regulated by numerous MADS Box genes, auxin associated genes and several novel transcription factors (Mao et al., 2000; Nakano et al., 2013; Guan et al., 2014; Ito and Nakano, 2015; Ma et al., 2015). Researchers have also extensively studied the role of cell wall hydrolytic enzymes and polysaccharides including cellulases, polygalacturonases, pectinases, xyloglucans, arabinans, and galactans during tomato fruit abscission (del Campillo and Bennett, 1996; Kalaitzis et al., 1997; Iwai et al., 2013). Many of the cell-wall associated genes are members of large gene families; and thus, efforts to alter the abscission process through modification of these genes have not yielded significant changes. In addition not all ethylene associated genes that have been shown to affect abscission in Arabidopsis delay abscission in tomato. While mutations in ETR1, ETR2, and ETR3 all delay the process of abscission in Arabidopsis, only the mutated ortholog of ETR1 (NEVERRIPE) delays abscission in tomato; and they all are primarily associated with fruit ripening (Lanahan et al., 1994; Klee, 2002). Historically, breeders have focused on fruit size, color, and flavor rather than abscission. Perhaps the marketing of increased tomato varieties in markets and the new emphasis on local produce, abscission in cluster tomatoes may warrant further study on abscission in tomatoes.

\section{Approaches to Study Abscission in Both the Grasses and Dicots}

Many of the genes found in maize, rice, and Arabidopsis are highly conserved and plant breeders have embraced this knowledge to direct research programs toward utilizing genomic approaches. With the tools and knowledge to identify and engineer alternative plant species, will these efforts prove productive? There is no doubt that as the world population grows and resources and climate conditions change, it is critical that we continue to increase crop production and develop more sustainable agricultural practices. While there are 100s of crops to consider, this manuscript will use examples such as tomato (an annual vegetable crop), grapes (a perennial fruit tree crop), cranberries 

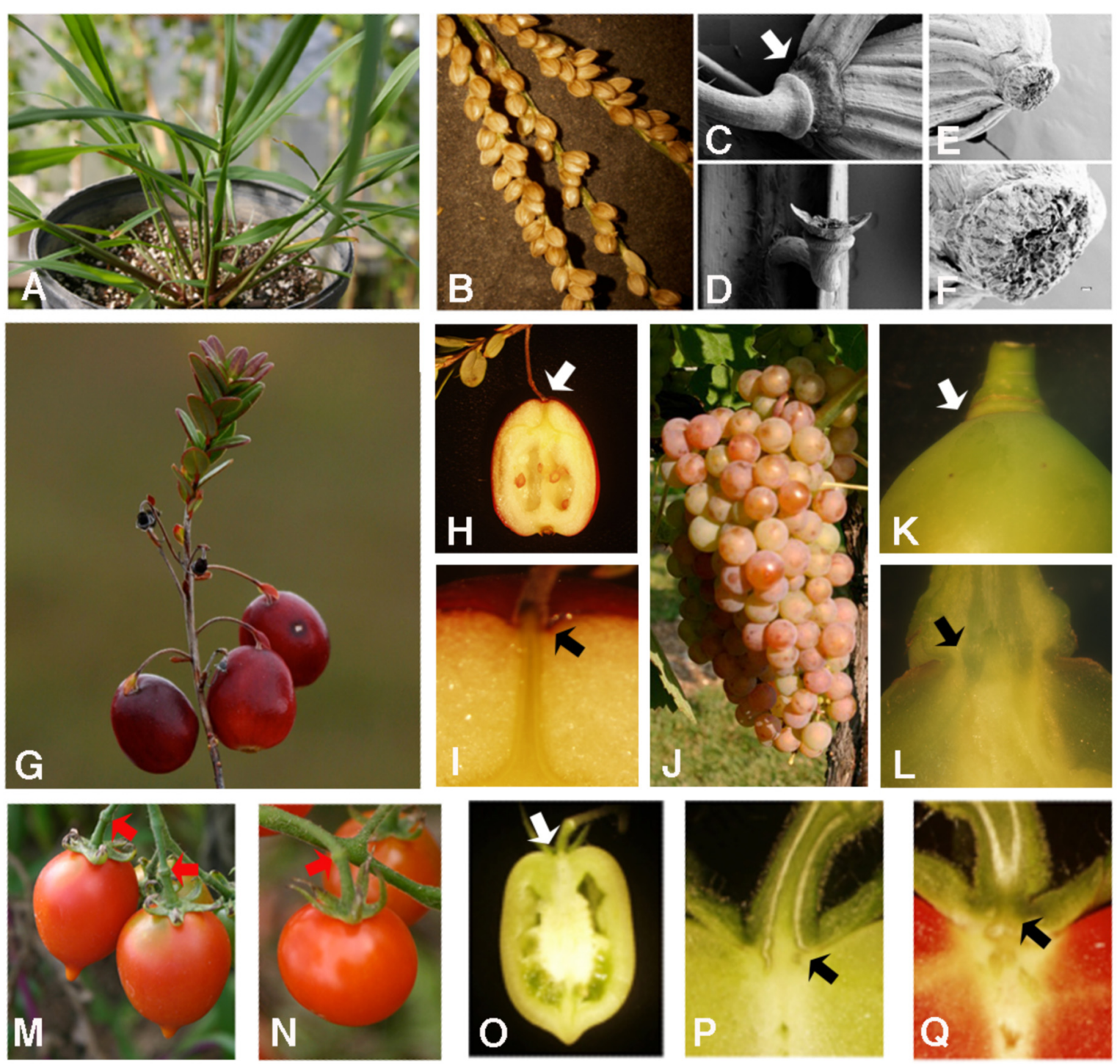

FIGURE 2 | Abscission in fonio, cranberry, grapes, and tomatoes. (A-F) Images of fonio illustrating the developing plant (A), a mature inflorescence (B), and scanning electron micrographs of the abscission zone of a mature seed (C-F). (G-I) Images of cranberry illustrating the developing fruit (G) and sections revealing

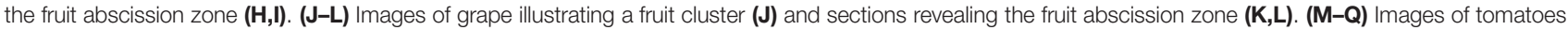
illustrating the abscission zones in tomatoes. A variety of cultivars were observed and pictured are two cluster varieties: Principe Borghese (M), and Ladybug (N). (O-Q) Illustrate freehand sections of the pedicel abscission zone attached directly to the developing fruit. Black and white arrows show fruit/pedicel abscission zones and red arrows show the "knuckle" abscission zone.

(a perennial fruit crop), and fonio (an annual grass native to West Africa). These crops have been selected to provide a perspective on both well-studied crops and less developed crops (Figure 2).

\section{Crop Examples}

\section{Fonio - An Orphan Grass: Challenges and Success}

Our major grain crops including maize, wheat, and barley have been selected for delayed abscission by early gatherers for thousands of years. In addition, some millet varieties that have been cultivated for centuries have reduced shatter (Zohary and Hopf, 2000; Brink and Belay, 2006). However, uncontrolled seed shatter in fonio Digitaria exilis and many of the orphan grain crops is one of the growers' greatest concerns and a major limiting factor in their potential for expansion as food crops. These orphan grain crops are often drought and disease resistant and small plots are routinely grown in many communities. Addressing seed shattering in crops such as fonio could increase yields by more than a third, providing farmers significant additional income (Foltz, personal communication). Of major importance is that this could be done with out adding fertilizer. In contrast to other commonly grown grains, fonio requires little or no inputs; thus not requiring additional investment by farmers. For example, in Mali, yields of common millet could be improved with fertilizer applications, yet this would require investment; 
and, predicted profits from a 50\% increase in yield due to these added resources would not exceed the predicted profits from improved fonio with reduced shattering. As the world population grows and climate conditions change, resource management is critical and thus attention to breeding and management practices for small orphan grains has become extremely important.

Currently, fonio is grown extensively in Guinea, Gambia, Senegal, Mali, Burkina Faso, Benin, Senegal, Togo, Nigeria, and the Dominican Republic. In most of West Africa, fonio is grown primarily by smallholders on plots typically of one hectare or less; and harvest must be performed within a couple days of full grain development due to seed shatter. Abscission, or seed shatter in fonio has not been studied in the past; and thus, one of the first challenges has been to characterize flowering and the abscission process. We have observed that flowering in fonio is tightly regulated, as initially reported by KwonNdung and Misari (1999), Cruz (2004), Cruz et al. (2006), Tekete (2006), and Cruz and Béavogui (2011). This photoperiodic control of flowering and seed development results in the narrow window for harvest. We also believe that abscission in fonio is both environmentally and developmentally regulated, and grains abscise with the first heavy rainfall after reaching full maturity. These observations propelled us to identify genetic factors regulating abscission as modification of weather or flowering time was less achievable.

Since there was initially no sequence data on fonio, we performed a single Illumina sequence run to generate a snapshot of the transcriptome of a Niatia seedling (one of the most common commercially available lines). The run yielded 38 million reads that we mapped directly onto to the rice genome and the rice transcriptome, as well as assembled de novo. We aligned contigs from the transcript assembly with the sequence of several known shattering genes and their homologs in maize, rice, and sorghum, and found extensive fonio sequence similarities with the rice shattering gene $q S H 1$, members of the Agamousrelated family of genes such as JOINTLESS 1-3, SH2, and SH3, the free-threshing locus $Q$ of wheat, as well as the Arabidopsis abscission-associated gene NEVERSHED (Liljegren et al., 2009; Sang, 2009). Using this sequence information we have been able to PCR amplify portions of the qSH1 homolog from fonio genomic DNA. While this provides proof of principle, it still needs to be determined if selection for mutants in $q S H 1$ would provide a delay in seed shatter. As fonio seed is quite small like Arabidopsis, a targeted approach to screen mutagenized seed similar to iTILLING could be utilized (Bush and Krysan, 2010).

Overall, there are gains to be made through targeted gene selection in fonio and other small orphan grains; but the challenges still remain. Selection of cultivars/lines to study is one of the first questions, as historically each community has their own local lines. Some lines are diploid and others thought to be tetraploid. In addition, fonio is self-pollinated and potentially apomictic; and thus, crosses between lines are challenging. Techniques for pollination of finger millet have been developed by the Devos and Bennetzen labs at the University of Georgia and are being applied to crossing fonio. Communication with remote villages and farmers as well as distribution of new seed and management practices will also be challenging. However, despite these concerns, crops like fonio have significant potential for increases in yield by understanding the abscission process and breeding for genes regulating seed shatter.

\section{Woody Perennial Dicots: Cranberries and Grapes-Challenges and Successes}

Historically berry drop or abscission has not been a trait that either grape or cranberry growers have focused on improving. However, with the recent focus on conservation of water and resources and the introduction of new cold-hardy hybrid grapes (Vitis vinifera $\times$ Vitis riparia and Vitis vinifera $\times$ Vitis labrusca) berry drop has become an issue in both crops. With wine grapes, early abscission results in lower sugar content and higher acidity, and thus a poorer quality wine in general. Alternatively, in table grapes it is even more important to retain high quality full clusters after harvest. Uncontrolled berry drop decreases both value and quality. Curiously, increased berry drop in some cultivars such as "Sunpreme" may prove fruitful for raisin producers, as some growers are now taking advantage of berry abscission to reduce harvest costs (Romero, 2015). In cranberry, there has been minimal research regarding abscission, but it is believed that cultural and environmental factors such as limited nutrient availability and extreme heat conditions can cause fruit drop. Growers have placed a new emphasis on management of water and sustainable production in response to climate change and new environmental stresses. Consequently, the loss of fruit is an important issue as fruit growth and abscission is most likely dependent on transport of water, nutrients and other factors across this zone (Sawicki et al., 2015).

We searched available databases for both grapes and cranberries for orthologs to 15 genes previously identified in Arabidopsis that have been characterized as regulating the abscission process or associated with unique stages of development in the abscission process (Supplementary Table S1). In grapes (Vitis vinifera), we selected orthologs for ten genes (NCBI); and are currently looking at gene expression during the abscission process in four hybrid cultivars of coldhardy Wisconsin grapes. In cranberry, joint efforts across the United States have recently yielded a transcriptome and nuclear genome assembly (Polashock et al., 2014) and a nuclear genome assembly (Fajardo et al., 2014). We used both of these cranberry generated databases to search for abscission genes. While matches for all fifteen of the genes we searched for were identified in both grape and cranberry genomes, too many close matches to identify a single ortholog was frequently an issue (Supplementary Table S1). In general, the high homology of both cranberry and grape genes to known abscission-related genes from Arabidopsis suggests that there may be shared functions and similar signaling pathways regulating the abscission process. Identification of the best candidate ortholog, transcription factors and unique aspects of development associated with each species may make altering abscission more challenging. Ultimately, improving our understanding of both early and late fruit abscission in these fruit crops using molecular tools combined with traditional breeding, morphological and physiological studies will lead to better management practices and improved quality and greater yields. 


\section{SUMMARY: WHY THE SUCCESS IN SOME CROPS AND NOT OTHERS?}

Building our knowledge on abscission in crop plants continues to be an important challenge not only not to prevent unwanted abscission but also to promote early abscission, as in many cases early bud removal and accelerated fruit abscission promotes improved root development, a more vigorous plant, and higher quality fruit and flowers. The rapid advances in molecular techniques and availability of quality sequence information on most species has spurred interest and promoted new research on the cloning and engineering known genes. While many of these genes will definitely have similar functions in many crops, researchers must always pause and remember the developmental biology of their plant such as flowering time, pollination, fertility, fruit development, life cycle, and senescence. Crops may vary as to whether they abscise at the abscission zone associated directly with the fruit or at an independent zone within the pedicel; and thus knowing the biology and marketing traits of the crop must be considered. In addition, developmental programs may mask other traits; and thus, a gene altering the abscission process may have no effect in specific genetic backgrounds. This is the case in the recently discovered role of panicle structure in rice and the hidden role in abscission (Ishii et al., 2013). Clearly, it is essential that breeders and molecular biologists work together providing an understanding of the unique development of each species as well as the targeted genes or pathways of interest. Similarly, it will also be critical to consider genome size, ploidy, and genetic relationships amongst lines as well as between species. Our progress may be

\section{REFERENCES}

Aalen, R. B., Butenko, M. A., Stenvik, G.-E., Tandstad, N. M., and Patterson, S. E. (2006). "Genetic control of floral abscission," in Floriculture, Ornamental and Plant Biotechnology: Advances and Topical Issues, ed. J.T.d Silva (London: Global Science Books Ltd.), 101-108.

Aalen, R. B., Wildhagen, M., Stø, I. M., and Butenko, M. A. (2013). IDA: a peptide ligand regulating cell separation processes in Arabidopsis. J. Exp. Bot. 64, 5253-5261. doi: 10.1093/jxb/ert338

Abeles, F. B. (1969). Abscission: role of cellulase. Plant Physiol. 44, 447-452. doi: 10.1104/pp.44.3.447

Abeles, F. B., and Rubinstein, B. (1964). Regulation of ethylene evolution and leaf abscission by auxin. Plant Physiol. 39, 963-969. doi: 10.1104/pp.39. 6.963

Addicott, F. (1982). Abscission. Berkeley, CA: University of California Press.

Aida, M., and Tasaka, M. (2006). Genetic control of shoot organ boundaries. Curr. Opin. Plant Biol. 9, 72-77. doi: 10.1016/j.pbi.2005.11.011

Bar-Dror, T., Dermastia, M., Kladnik, A., Znidaric, M. T., Novak, M. P., Meir, S., et al. (2011). Programmed cell death occurs asymmetrically during abscission in tomato. Plant Cell 23, 4146-4163. doi: 10.1105/tpc.111.092494

Basu, M. M., González-Carranza, Z. H., Azam-Ali, S., Tang, S., Shahid, A. A., and Roberts, J. A. (2013). The manipulation of auxin in the abscission zone cells of Arabidopsis flowers reveals that indoleacetic acid signaling is a prerequisite for organ shedding. Plant Physiol. 162, 96-106. doi: 10.1104/pp.113. 216234

Binder, B., and Patterson, S. (2009). Ethylene-dependent and -independent regulation of abscission. Stewart Postharvest Rev. 5, 1-10. doi: 10.2212/spr.2009.1.1

Brink, M., and Belay, G. (2006). Plant Resources of Tropical Africa I: Cereals and Pulses. Wageningen: PROTA Foundation, 54-57. slow at times; but a concerted combined effort promises new insights.

\section{AUTHOR CONTRIBUTIONS}

AM, JB-M, JH, DN-M, TF, JZ, and SP designed the experiments. AM, JB-M, DN-M, TF, and SP performed the experiments. SP and $\mathrm{JZ}$ wrote and edited the manuscript. In addition, all authors contributed to editing the manuscript.

\section{FUNDING}

This research was supported by the College of Agricultural and Life Sciences and the Graduate School of the University of Wisconsin, and by grants from NSF 1250868/1063085 and SCBG-14-004.

\section{ACKNOWLEDGMENT}

The authors would like to thank members of the Patterson and Zalapa lab and the West Madison Agricultural Research Station for their helpful discussions.

\section{SUPPLEMENTARY MATERIAL}

The Supplementary Material for this article can be found online at: http://journal.frontiersin.org/article/10.3389/fpls.2015.01268

Bush, S. M., and Krysan, P. J. (2010). iTILLING: a personalized approach to the identification of induced mutations in Arabidopsis. Plant Physiol. 154, 25-35. doi: 10.1104/pp.110.159897

Butenko, M. A., Patterson, S. E., Grini, P. E., Stenvik, G. E., Amundsen, S. S., Mandal, A., et al. (2003). Inflorescence deficient in abscission controls floral organ abscission in Arabidopsis and identifies a novel family of putative ligands in plants. Plant Cell 15, 2296-2307. doi: 10.1105/tpc.014365

Butenko, M. A., Vie, A. K., Brembu, T., Aalen, R. B., and Bones, A. M. (2009). Plant peptides in signalling: looking for new partners. Trends Plant Sci. 14, 255-263. doi: 10.1016/j.tplants.2009.02.002

Cai, S., and Lashbrook, C. C. (2008). Stamen abscission zone transcriptome profiling reveals new candidates for abscission control: enhanced retention of oral organs in transgenic plants overexpressing Arabidopsis ZINC FINGER PROTEIN2. Plant Physiol. 146, 1305-1321. doi: 10.1104/pp.107.110908

Chen, M. K., Hsu, W. H., Lee, P. F., Thiruvengadam, M., Chen, H. L., and Yang, C. H. (2011). The MADS box gene, FOREVER YOUNG FLOWER, acts as a repressor controlling floral organ senescence and abscission in Arabidopsis. Plant J. 68, 168-185. doi: 10.1111/j.1365-313X.2011.04677.x

Chew, W., Hrmova, M., and Lopato, S. (2013). Role of homeodomain leucine zipper (HD-Zip) IV transcription factors in plant development and plant protection from deleterious environmental factors. Int. J. Mol. Sci. 14, 81228147. doi: 10.3390/ijms14048122

Cho, H. T., and Cosgrove, D. J. (2000). Altered expression of expansin modulates leaf growth and pedicel. Proc. Natl. Acad. Sci. U.S.A. 97, 9783-9788. doi: $10.1073 /$ pnas. 160276997

Cruz, J. F. (2004). Fonio: a small grain with potential. LEISA Magazine 20, 16-17.

Cruz, J. F., and Béavogui, F. (2011). Le Fonio, une Céréale Africaine. Versailles: Quae.

Cruz, J. F., Drame, D., Kouyate, S., Marouzé, C., Sakho, S., and Son, G. (2006). "Improvement of fonio post-harvest technology. Mechanization of processing 
operations," in Proceedings of Technological Innovation and Enhancement of Marginal Products: Foggia, 6-8 April 2005, eds C. Severini, T. De Pilli, and R. Giuliani (Foggia: Claudio Grenzi), 256-257.

del Campillo, E. (1999). Multiple endo-1,4-beta-D-glucanase (cellulase) genes in Arabidopsis. Curr. Top. Dev. Biol. 46, 39-61. doi: 10.1016/S00702153(08)60325-7

del Campillo, E., and Bennett, A. B. (1996). Pedicel break strength and cellulase gene expression during tomato flower abscission. Plant Physiol. 111, 813-820. doi: $10.1104 /$ pp.111.3.813

Dwivedi, K. K., Roche, D. J., Clemente, T. E., Ge, Z., and Carman, J. G. (2014). The OCL3 promoter from Sorghum bicolor directs gene expression to abscission and nutrient-transfer zones at the bases of floral organs. Ann. Bot. 114, 489-498. doi: 10.1093/aob/mcu148

Ellis, C. M., Nagpal, P., Young, J. C., Hagen, G., Guilfoyle, T. J., and Reed, J. W. (2005). AUXIN RESPONSE FACTOR1 and AUXIN RESPONSE FACTOR2 regulate senescence and floral organ abscission in Arabidopsis thaliana. Development 132, 4563-4574. doi: 10.1242/dev.02012

Estornell, L. H., Agusti, J., Merelo, P., Talon, M., and Tadeo, F. R. (2013). Elucidating mechanisms underlying organ abscission. Plant Sci. 19, 48-60. doi: 10.1016/j.plantsci.2012.10.008

Fajardo, D., Schlautman, B., Steffan, S., Polashock, J., Vorsa, N., and Zalapa, J. (2014). The American cranberry mitochondrial genome reveals the presence of selenocysteine (tRNA-Sec and SECIS) insertion machinery in land plants. Gene 536, 336-343. doi: 10.1016/j.gene.2013.11.104

Farage-Barhom, S., Burd, S., Sonego, L., Perl-Treves, R., and Lers, A. (2008). Expression analysis of the BFN1 nuclease gene promoter during senescence, abscission, and programmed cell death-related processes. J. Exp. Bot. 59, $3247-$ 3258. doi: 10.1093/jxb/ern176

Fernandez, D. E., Heck, G. R., Perry, S. E., Patterson, S. E., Bleecker, A. B., and Fang, S. C. (2000). The embryo MADS domain factor AGL15 acts postembryonically. Inhibition of perianth senescence and abscission via constitutive expression. Plant Cell 12, 183-198. doi: 10.1105/tpc.12.2.183

Gonzalez-Carranza, Z. H., Elliott, K. A., and Roberts, J. A. (2007a). Expression of polygalacturonases and evidence to support their role during cell separation processes in Arabidopsis thaliana. J. Exp. Bot. 58, 3719-3730. doi: 10.1093/jxb/erm 222

Gonzalez-Carranza, Z. H., Rompa, U., Peters, J. L., Bhatt, A. M., Wagstaff, C., Stead, A. D., et al. (2007b). HAWAIIAN SKIRT: an F-box gene that regulates organ fusion and growth in Arabidopsis. Plant Physiol. 144, 1370-1382. doi: 10.1104/pp.106.092288

Gonzalez-Carranza, Z., Whitelaw, C., Swarup, R., and Roberts, J. (2002). Temporal and spatial expression of a polygalacturonase during leaf and flower abscission in oilseed rape and Arabidopsis. Plant Physiol. 128, 534-543. doi: 10.1104/pp.010610

Guan, X., Xu, T., Gao, S., Qi, M., Wang, Y., Xin, L., et al. (2014). Temporal and spatial distribution of auxin response factor genes during tomato flower abscission. J. Plant Growth Regul. 33, 317-327. doi: 10.1007/s00344-013-9377-x

Harlan, J. R. (1992). Crops and Man, 2nd Edn. Madison, WI: American Society of Agronomy and Crop Science Society of America.

Hepworth, S. R., Zhang, Y., McKim, S., Li, X., and Haughn, G. W. (2005). BLADE-ON-PETIOLE-dependent signaling controls leaf and floral patterning in Arabidopsis. Plant Cell 17, 1434-1448. doi: 10.1105/tpc.104.030536

Ishii, T., Numaguchi, K., Miura, K., Yoshida, K., Thanh, P. T., Htun, T. M., et al. (2013). OsLG1 regulates a closed panicle trait in domesticated rice. Nat. Genet. 45, 462-465. doi: 10.1038/ng.2567

Ito, Y., and Nakano, T. (2015). Development and regulation of pedicel abscission in tomato. Front. Plant Sci. 6:442. doi: 10.3389/fpls.2015.00442

Iwai, H., Tarao, A., and Satoh, S. (2013). Changes in distribution of cell wall polysaccharides in floral and fruit abscission zones during fruit development in tomato (Solanum lycopersicum). J. Plant Res. 126, 427-437. doi: 10.1007/s10265-012-0536-0

Jensen, T. E., and Valdovinos, J. G. (1967). Fine structure of abscission zones I. Abscission zones of the pedicels of tobacco and tomato flowers at anthesis. Planta 77, 298-318. doi: 10.1007/BF00389317

Jinn, T.-L., Stone, J. M., and Walker, J. C. (2000). HAESA, an Arabidopsis leucinerich repeat receptor kinase, controls floral organ abscission. Genes Dev. 14, $108-117$.
Kalaitzis, P., Solomos, T., and Tucker, M. L. (1997). Three different polygalacturonases are expressed in tomato leaf and flower abscission, each with a different temporal expression pattern. Plant Physiol. 113, 1303-1308. doi: $10.1104 /$ pp.113.4.1303

Kim, J. (2014). Four shades of detachment: regulation of floral organ abscission. Plant Signal. Behav. 9, e976154. doi: 10.4161/15592324.2014.976154

Kim, J., Dotson, B., Rey, C., Lindsey, J., Bleecker, A. B., Binder, B. M., et al. (2013). New clothes for the jasmonic acid receptor COI1: delayed abscission, meristem arrest and apical dominance. PLOS ONE 8:e60505. doi: 10.1371/journal.pone.0060505

Kim, J., and Patterson, S. E. (2006). Expression divergence and functional redundancy of polygalacturonases in floral organ abscission. Plant Signal. Behav. 1, 281-283. doi: 10.4161/psb.1.6.3541

Kim, J., Shiu, S.-H., Thoma, S., Li, W.-H., and Patterson, S. E. (2006). Patterns of expansion and expression divergence in the plant polygalacturonase gene family. Genome Biol. 7, R87. doi: 10.1186/gb-2006-7-7-323

Klee, H. J. (2002). Control of ethylene-mediated processes in tomato at the level of receptors. J. Exp. Bot. 53, 2057-2063. doi: 10.1093/jxb/erf062

Konishi, S., Izawa, T., Lin, S. Y., Ebana, K., Fukuta, Y., Sasaki, T., et al. (2006). An SNP caused loss of seed shattering during rice domestication. Science 312, 1392-1396. doi: 10.1126/science. 1126410

Kwon-Ndung, E. H., and Misari, S. M. (1999). "Overview of research and development of fonio (Digitaria exilis Kippis Stapf) and prospects for genetic improvement in Nigeria," in Genetics and Food Security in Nigeria (Nigeria: GSN Publication), 71-76.

Lanahan, M. B., Yen, H. C., Giovannoni, J. J., and Klee, H. J. (1994). The Never ripe mutation blocks ethylene perception in tomato. Plant Cell 6, 521-530. doi: 10.1105/tpc.6.4.521

Lashbrook, C. C., and Cai, S. (2008). Cell wall remodeling in Arabidopsis stamen abscission zones: temporal aspects of control inferred from transcriptional profiling. Plant Signal. Behav. 3, 733-736. doi: 10.4161/psb.3.9.6489

Leslie, M. E., Lewis, M. W., Youn, J.-Y., Daniels, M. J., and Liljegren, S. J. (2010). The EVERSHED receptor-like kinase modulates floral organ shedding in Arabidopsis. Development 137, 467-476. doi: 10.1242/dev.041335

Lewis, M. W., Leslie, M. E., and Liljegren, S. J. (2006). Plant separation: 50 ways to leave your mother. Curr. Opin. Plant Biol. 9, 59-65. doi: 10.1016/j.pbi.2005.11.009

Li, C., Zhou, A., and Sanng, T. (2006). Rice domestication by reducing shattering. Science 311, 1936-1939. doi: 10.1126/science.1123604

Liljegren, S. J. (2012). Organ abscission: exit strategies require signals and moving traffic. Curr. Opin. Plant Biol. 15, 670-676. doi: 10.1016/j.pbi.2012.09.012

Liljegren, S. J., Leslie, M. E., Darnielle, L., Lewis, M. W., Taylor, S. M., Luo, R., et al. (2009). Regulation of membrane trafficking and organ separation by the NEVERSHED ARF-GAP protein. Development 136, 1909-1918. doi: 10.1242/dev.033605

Ma, C., Meir, S., Xiao, L., Tong, J., Liu, Q., Reid, M. S., et al. (2015). A KNOTTED1LIKE HOMEOBOX protein regulates abscission in tomato by modulating the auxin pathway. Plant Physiol. 167, 844-853. doi: 10.1104/pp.114.253815

Mao, L., Begum, D., Chuang, H. W., Budiman, M. A., Szymkowiak, E. J., Irish, E. E., et al. (2000). JOINTLESS is a MADS-box gene controlling tomato flower abscission zone development. Nature 406, 910-913. doi: 10.1038/35 022611

McKim, S. M., Stenvik, G. E., Butenko, M. A., Kristiansen, W., Cho, S. K., Hepworth, S. R., et al. (2008). The BLADE-ON-PETIOLE genes are essential for abscission zone formation in Arabidopsis. Development 135, 1537-1546. doi: 10.1242/dev.012807

Meng, X., Wang, H., He, Y., Liu, Y., Walker, J. C., Torii, K. U., et al. (2012). A MAPK cascade downstream of erecta receptor-like protein kinase regulates Arabidopsis inflorescence architecture by promoting localized cell proliferation. Plant Cell 24, 4958-4960. doi: 10.1105/tpc.112.104695

Nakano, T., Fujisawa, M., Shima, Y., and Ito, Y. (2013). Expression profiling of tomato pre-abscission pedicels provides insights into abscission zone properties including competence to respond to abscission signals. BMC Plant Biol. 13:40. doi: 10.1186/1471-2229-13-40

Niederhuth, C. E., Cho, S. K., Seitz, K., and Walker, J. C. (2013). Letting go is never easy: abscission and receptor-like protein kinases. J. Integr. Plant Biol. 55, 1251-1263. doi: 10.1111/jipb.12116 
Ogawa, M., Kay, P., Wilson, S., and Swain, S. M. (2009). ARABIDOPSIS DEHISCENCE ZONE POLYGALACTURONASE1 (ADPG1), ADPG2, and QUARTET2 are polygalacturonases required for cell separation during reproductive development in Arabidopsis. Plant Cell 21, 216-233. doi: 10.1105/tpc.108.063768

Osborne, D. J. (1989). Abscission. Crit. Rev. Plant Sci. 8, 103-129. doi: $10.1080 / 07352688909382272$

Patterson, S. E. (2001). Cutting loose. Abscission and dehiscence in Arabidopsis. Plant Physiol. 126, 494-500. doi: 10.1104/pp.126.2.494

Patterson, S. E., and Bleecker, A. B. (2004). Ethylene-dependent and -independent processes associated with floral organ abscission in Arabidopsis. Plant Physiol. 134, 194-203. doi: 10.1104/pp.103.028027

Plants and Society (2006). Estelle Levetin and Karen McMahon, 5th Edn. New York City, NY: McGraw Hill, 184-236.

Polashock, J., Zelzion, E., Fajardo, D., Zalapa, J., Georgi, L., Bhattacharya, D., et al. (2014). The American cranberry: first insights into the whole genome of a species adapted to bog habitat. BMC Plant Biol. 14:165. doi: 10.1186/1471-222914-165

Pourkheirandish, M., Hensel, G., Kilian, B., Senthil, N., Chen, G., Sameri, M., et al. (2015). Evolution of the grain dispersal system in barley. Cell 162, 527-539. doi: 10.1016/j.cell.2015.07.002

Rast, M. I., and Simon, R. (2008). The meristem-to-organ boundary: more than an extremity of anything. Curr. Opin. Genet. Dev. 18, 287-294. doi: 10.1016/j.gde.2008.05.005

Roberts, J. A., Elliott, K. A., and Gonzalez-Carranza, Z. H. (2002). Abscission, dehiscence, and other cell separation processes. Annu. Rev. Plant Biol. 53, 131-158. doi: 10.1146/annurev.arplant.53.092701.180236

Roberts, J. A., Whitelaw, C. A., Gonzalez-Carranza, Z. H., and McManus, M. T. (2000). Cell separation processes in plants: models, mechanisms, and manipulation. Ann. Bot. 86, 223-235. doi: 10.1006/anbo.2000.1203

Romero, E. D. (2015). Sunpreme: The Grape That Could Revolutionize The Raisin Industry, NPR. Available at: http://www.npr.org/sections/thesalt/2015/10/07/ $446590533 /$ sunpreme-the-grape-that-could-revolutionize-the-raisin-industry

Sang, T. (2009). Genes and mutations underlying domestication transitions in grasses. Plant Physiol. 149, 63-70. doi: 10.1104/pp.108.128827

Sawicki, M., Barka, E. A., Clément, C., Vaillant-Gaveau, N., and Jacquard, C. (2015). Cross-talk between environmental stresses and plant metabolism during reproductive organ abscission. J. Exp. Bot. 66, 1707-1719. doi: 10.1093/jxb/eru533

Sexton, R., and Roberts, J. A. (1982). Cell biology of abscission. Annu. Rev. Plant Physiol. 33, 133-162. doi: 10.1146/annurev.pp.33.060182.001025

Shi, C.-L., Stenvik, G.-E., Vie, A. K., Bones, A. M., Pautot, V., Proveniers, M., et al. (2011). Arabidopsis class I KNOTTED-like homeobox proteins act downstream in the IDA-HAE/HSL2 floral abscission signaling pathway. Plant Cell 23, 2553-2567. doi: 10.1105/tpc.111.084608

Singh, A. P., Tripathi, S. K., Nath, P., and Sane, A. P. (2011). Petal abscission in rose is associated with the differential expression of two ethylene-responsive xyloglucan endotransglucosylase/hydrolase genes, RbXTH1, and RbXTH2. J. Exp. Bot. 62, 5091-5103. doi: 10.1093/jxb/err209

Stenvik, G., Tandstad, N., Guo, Y., and Shi, C. (2008). The EPI Peptide of INFLORESCENCE DEFICIENT IN ABSCISSION is sufficient to induce abscission in Arabidopsis through the receptor-like kinases HAESA and HAESA-LIKE2. Plant Cell 20, 1805-1817. doi: 10.1105/tpc.108.059139

Sundaresan, S., Philosoph-Hadas, S., Riov, J., Belausov, E., Kochanek, B., Tucker, M. L., et al. (2015). Abscission of flowers and floral organs is closely associated with alkalization of the cytosol in abscission zone cells. J. Exp. Bot. 66, 13551368. doi: 10.1093/jxb/eru483

Tekete, M. L. (2006). Etude du Photopériodisme du Fonio. Ph.D. thesis, Diplôme d'Ingénieur Agronome de l'Institut Polytechnique Rural de Formation et de Recherche Appliquée de Katibougou (IER), French.

Van Nocker, S. (2009). Development of the abscission zone. Stewart Postharvest Rev. 5, 1-6. doi: 10.2212/spr.2009.1.5

Wang, X., Xu, W. H., Ma, L., Fu, Z., Deng, X., Li, J., et al. (2006). Requirement of KNAT1/BP for the development of abscission zones in Arabidopsis thaliana. J. Integr. Plant Biol. 48, 15-26. doi: 10.1111/j.1744-7909.2005.00085.x-i1

Wei, P.-C., Tan, F., Gao, X.-Q., Zhang, Z.-Q., Wang, G.-Q., Xu, H., et al. (2010). Overexpression of AtDOF4.7, an Arabidopsis DOF family transcription factor, induces floral organ abscission deficiency in Arabidopsis. Plant Physiol. 153, 1031-1045. doi: 10.1104/pp.110.153247

Zhou, Y., Lu, D., Li, C., Luo, J., Zhu, B. F., Zhu, J., et al. (2012). Genetic control of seed shattering in rice by the APETALA2 transcription factor shattering abortion1. Plant Cell 24, 1034-1048. doi: 10.1105/tpc.111.094383

Zohary, D., and Hopf, M. (2000). Domestication of Plants in the Old World, 3rd Edn. Oxford: Oxford University Press, 16-91.

Conflict of Interest Statement: The authors declare that the research was conducted in the absence of any commercial or financial relationships that could be construed as a potential conflict of interest.

Copyright (C) 2016 Patterson, Bolivar-Medina, Falbel, Hedtcke, Nevarez-McBride, Maule and Zalapa. This is an open-access article distributed under the terms of the Creative Commons Attribution License (CC BY). The use, distribution or reproduction in other forums is permitted, provided the original author(s) or licensor are credited and that the original publication in this journal is cited, in accordance with accepted academic practice. No use, distribution or reproduction is permitted which does not comply with these terms. 